\title{
Carbon Dioxide Sensing Characteristics of AlGaN/GaN High Electron Mobility Transistor with ZnO Nanorods
}

\author{
Kwang Hyeon Baik ${ }^{1}$ and Soohwan Jang ${ }^{2 *}$ \\ ${ }^{1}$ Department of Materials Science and Engineering, Hongik University, \\ 2639 Sejong-ro, Jochiwon, Sejong 30016, Republic of Korea \\ ${ }^{2}$ Department of Chemical Engineering, Dankook University, \\ 152 Jukjeon-ro, Suji-gu, Yongin-si, Gyeonggi-do 16890, Republic of Korea
}

(Received April 7, 2020; accepted June 2, 2020)

Keywords: carbon dioxide, gas sensor, $\mathrm{AlGaN} / \mathrm{GaN}, \mathrm{HEMT}, \mathrm{ZnO}$

A $\mathrm{CO}_{2}$ sensor based on an $\mathrm{AlGaN} / \mathrm{GaN}$ high electron mobility transistor (HEMT) was developed using $\mathrm{ZnO}$ nanorods as the sensing material. The sensor showed a reliable response to a wide range of $\mathrm{CO}_{2}$ concentrations from 500 to $100000 \mathrm{ppm}$ at $300{ }^{\circ} \mathrm{C}$. The $\mathrm{CO}_{2}$ response of the device was tested from 25 to $400{ }^{\circ} \mathrm{C}$, and the sensor started to exhibit responsivity to $30000 \mathrm{ppm} \mathrm{CO}_{2}$ gas at $150{ }^{\circ} \mathrm{C}$. The responsivity increased with the ambient temperature until the temperature reached $300{ }^{\circ} \mathrm{C}$, and it decreased from 350 to $400{ }^{\circ} \mathrm{C}$. The maximum responsivity of the sensor with $\mathrm{ZnO}$ nanorods was $4.31 \%$ for $10 \% \mathrm{CO}_{2}$ exposure at $300{ }^{\circ} \mathrm{C}$. In addition, the effect of humidity on the $\mathrm{CO}_{2}$ sensing characteristics was investigated. $\mathrm{AlGaN} / \mathrm{GaN}$-heterostructure-based $\mathrm{CO}_{2}$ sensors functionalized with $\mathrm{ZnO}$ nanorods have high potential for applications in the chemical, medical, energy, and food industries.

\section{Introduction}

There has been much interest in $\mathrm{CO}_{2}$ sensors for monitoring global warming, indoor air quality, process control in fermentation, and medical use. ${ }^{(1,2)}$ The concentration of atmospheric $\mathrm{CO}_{2}$ was $280 \mathrm{ppm}$ before the industrial revolution, which increased to $400 \mathrm{ppm}$ with the increase in fossil fuel usage. ${ }^{(3)} \mathrm{CO}_{2}$ is colorless and odorless, and its molecular mass is $44.01 \mathrm{~g} / \mathrm{mol}$, which is heavier than air $(18.02 \mathrm{~g} / \mathrm{mol})$. Hence, it easily accumulates on the ground of an enclosed space. A $\mathrm{CO}_{2}$ concentration of more than $7 \%$ can cause acute symptoms in exposed people including unconsciousness, even in environments with high concentrations of oxygen. For example, a worker in an isolated septic tank with a high concentration of $\mathrm{CO}_{2}$ can become unconscious and die in severe cases. $\mathrm{CO}_{2}$ is used for reactants, intermediates, and products in the chemical, medical, energy, and food industries. It is necessary to detect promptly the specific concentration of $\mathrm{CO}_{2}$ for the safety of workplaces and the health of workers, as well as to monitor indoor air quality in daily life.

The most conventional approach to detecting $\mathrm{CO}_{2}$ is based on nondispersive infrared absorption sensors, which consist of an infrared source, a light tube, an interface filter, "Corresponding author: e-mail: jangmountain@dankook.ac.kr https://doi.org/10.18494/SAM.2020.2900 
and an infrared detector. ${ }^{(4,5)}$ They have good sensitivity and selectivity for $\mathrm{CO}_{2}$ sensing, but they require high power consumption, a large physical space, and a complex structure. Semiconductor-based gas sensors have many merits, such as low power consumption, compact size, sensitivity, and reliability. ${ }^{(5)}$ Among the many semiconductor materials, GaN-based material systems are highly suitable for gas sensing. GaN-based gas sensors exhibit high signal-to-noise ratios, and they have reliable and stable operation at high temperatures owing to their excellent material properties, such as a wide energy bandgap of $3.4 \mathrm{eV}$, chemical and mechanical robustness, excellent carrier transport, and radiation hardness. ${ }^{(6-24)}$ One of the biggest advantages of GaN-based semiconductors is the availability of the AlGaN/GaN heterostructure, in which a two-dimensional electron gas (2DEG) channel with a mobility of more than $1500 \mathrm{~cm}^{2} / \mathrm{V} \cdot \mathrm{s}$ forms at the interface between $\mathrm{AlGaN}$ and $\mathrm{GaN}$ due to spontaneous polarization and piezoelectric effects. ${ }^{(6-9,18-24)}$ The electron conductivity of the 2DEG is sensitive to changes in charge on the top AlGaN surface. In the sensor structure of an $\mathrm{AlGaN} / \mathrm{GaN}$ high electron mobility transistor (HEMT), the gate region is functionalized with a specific catalytic material to induce the decomposition reaction of the target gas. This results in a change in surface charge on the $\mathrm{AlGaN}$ surface. Monitoring the drain current passing through the 2DEG in the HEMT enables the output sensing signal for the decomposition reaction of the target gas to be obtained.

$\mathrm{ZnO}$ is a direct-bandgap semiconducting material with a wide bandgap energy of $3.37 \mathrm{eV}$ and a large exciton binding energy of $60 \mathrm{meV} .^{(25-27)} \mathrm{ZnO}$ nanostructures are grown by a simple hydrothermal method, which is a low-cost, nontoxic, low-temperature, and scalable process. During hydrothermal growth, the growth rate of the $c$-plane is higher than that of the $m$-plane in the wurtzite crystal structure because of the higher surface energy of the $c$-plane; $\mathrm{ZnO}$ nanowires or bundles of nanorods along the $c$-axis are generally formed during the hydrothermal synthesis process. ${ }^{(27-30)}$ These $\mathrm{ZnO}$ nanorods with high surface-to-volume ratio can be employed in $\mathrm{AlGaN} / \mathrm{GaN}$ HEMT gas sensors in the gate region to achieve high sensitivity to the target gas.

In this research, an $\mathrm{AlGaN} / \mathrm{GaN}$ HEMT-based $\mathrm{CO}_{2}$ sensor using $\mathrm{ZnO}$ nanorods as a sensing material was fabricated, and its $\mathrm{CO}_{2}$ sensing characteristics were investigated. The effects of temperature, $\mathrm{CO}_{2}$ concentration, and humidity on the $\mathrm{CO}_{2}$ responsivity were studied.

\section{Materials and Methods}

The AlGaN/GaN heterostructure was grown by metal organic chemical vapor deposition on a $c$-plane $\mathrm{Al}_{2} \mathrm{O}_{3}$ substrate. ${ }^{(6-9)}$ The epitaxial layer consisted of $2.5 \mu \mathrm{m} \mathrm{GaN}$ and $30 \mathrm{~nm}$ $\mathrm{Al}_{0.3} \mathrm{GaN}$. The sheet resistance, sheet carrier concentration, and carrier mobility of the AlGaN/GaN heterostructure were $320 \mathrm{ohm} /$ square, $9 \times 10^{12} \mathrm{~cm}^{-2}$, and $1800 \mathrm{~cm}^{2} / \mathrm{V} \cdot \mathrm{s}$, respectively. Figure 1 shows a top-view scanning electron microscopy (SEM) image of the HEMT with $\mathrm{ZnO}$ nanorods on the gate region and a schematic cross-sectional diagram of the HEMT structure along the cutline of $\mathrm{A}-\mathrm{A}^{\prime}$ in (a). The fabrication of the device started with $75 \mathrm{~nm}$ mesa isolation achieved by inductively coupled plasma etching with $\mathrm{Ar} / \mathrm{Cl}_{2}$ gas. A $20 \mathrm{~nm} \mathrm{Ti} / 80 \mathrm{~nm} \mathrm{Al} / 40 \mathrm{~nm} \mathrm{Ni} / 80 \mathrm{~nm} \mathrm{Au}$ metal stack was deposited by electron beam 


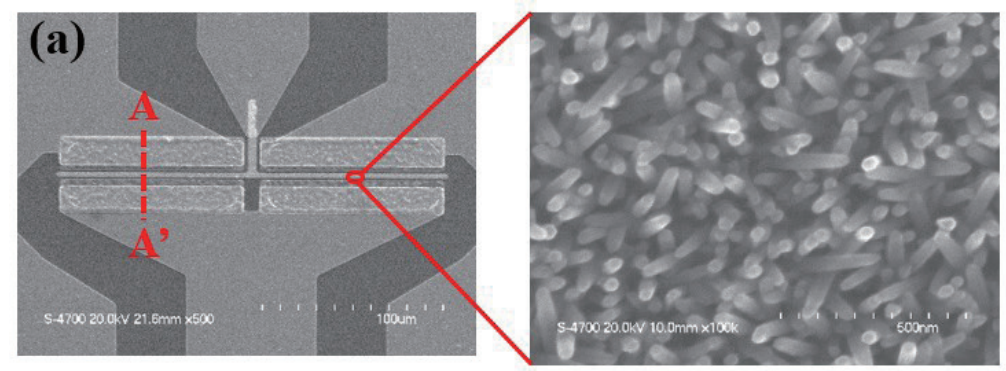

(b)

\begin{tabular}{|c|c|c|}
\hline pad metal & $\mathrm{ZnO}$ nanorods & pad metal \\
\hline source & 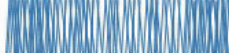 & drain \\
\hline \multicolumn{3}{|c|}{$\mathbf{A l}_{0.3} \mathbf{G a N}$} \\
\hline & c-plane GaN & 2 DEG \\
\hline & Sapphire & \\
\hline
\end{tabular}

Fig. 1. (Color online) (a) Top-view SEM image of the HEMT with $\mathrm{ZnO}$ nanorods and enlarged image of the $\mathrm{ZnO}$ nanorods. (b) Schematic cross-sectional diagram of the HEMT structure along the cutline of A-A' in (a).

evaporation, and the stack was annealed at $950{ }^{\circ} \mathrm{C}$ for 1 min under a $\mathrm{N}_{2}$ atmosphere by rapid thermal annealing for ohmic contact formation. A $20 \mathrm{~nm} \mathrm{Ti} / 120 \mathrm{~nm}$ Au pad metal was formed by electron beam evaporation for electrical signal probing. $\mathrm{ZnO}$ nanorods were selectively grown on the gate area by conventional photolithography, a simple hydrothermal $\mathrm{ZnO}$ nanorod growth method, ${ }^{(27-30)}$ and a lift-off process. A $25 \mathrm{mM}$ solution of zinc nitrate hexahydrate was dissolved in deionized water, and a $25 \mathrm{mM}$ methenamine solution was prepared. These two solutions were mixed together equivolumetrically in a Teflon-lined autoclave to prepare a growth solution. The fabricated $\mathrm{AlGaN} / \mathrm{GaN}$ HEMT substrate was suspended upside down in the growth solution and was placed in a $90{ }^{\circ} \mathrm{C}$ oven for 90 min. After the growth, the sample was removed, washed with deionized water vigorously, and blow-dried with nitrogen. This growth cycle was repeated five times to obtain dense $\mathrm{ZnO}$ nanorods with a high aspect ratio. The length and diameter of the $\mathrm{ZnO}$ nanorods were approximately $1 \mu \mathrm{m}$ and $50 \mathrm{~nm}$, respectively.

The drain current-voltage characteristics and current response of the HEMT sensor with $\mathrm{ZnO}$ nanorods were measured using an Agilent $4156 \mathrm{C}$ semiconductor parameter analyzer with the device in a gas test chamber under ambient conditions of various concentrations of $\mathrm{CO}_{2}$ in air. The temperature and humidity of the test ambient conditions were controlled respectively by the heater chuck on which the sample was placed and the humidity controller connected to the gas test chamber. 


\section{Results and Discussion}

Figure 2 shows the drain $I-V$ characteristics of the AlGaN/GaN HEMT with $\mathrm{ZnO}$ nanorods under air and a $10 \% \mathrm{CO}_{2}$ atmosphere at $300{ }^{\circ} \mathrm{C}$. When the device was exposed to $\mathrm{CO}_{2}$ gas, the drain current increased. In the $\mathrm{AlGaN} / \mathrm{GaN}$ heterostructure, a $2 \mathrm{DEG}$ channel layer exists underneath the $\mathrm{AlGaN}$ owing to polarization and piezoelectric effects, as shown in Fig. 1(b). ${ }^{(6-9,18,19)}$ The conductivity of the 2 DEG channel was affected sensitively by the change in charge on the AlGaN surface. If a reaction inducing the change in surface charge on the AlGaN surface by a target gas occurs, the conductivity of the $2 \mathrm{DEG}$ changes, resulting in a change in the drain current of the AlGaN/GaN HEMT. In the case of the $\mathrm{CO}_{2}$ atmosphere, the possible sensing mechanism of the AlGaN/GaN HEMT with $\mathrm{ZnO}$ nanorods is described as follows. $\mathrm{ZnO}$ is known to adsorb oxygen ions on the surface. ${ }^{(1,2,5)}$ The exposed $\mathrm{CO}_{2}$ gas molecules react with the adsorbed $\mathrm{O}^{-}$and release electrons with a negative charge. These electrons make the oxide more negative and induce an additional positive charge on the AlGaN surface, which enhances the 2DEG channel by accumulating more electrons and increasing the drain current of the device.

$$
\mathrm{CO}_{2}(\mathrm{~g})+\mathrm{O}^{-}(\mathrm{ad}) \leftrightarrow \mathrm{CO}(\mathrm{g})+\mathrm{O}_{2}(\mathrm{~g})+\mathrm{e}^{-}
$$

It is notable that the increase in drain current upon $\mathrm{CO}_{2}$ exposure is opposite to the case of reducing $\mathrm{NH}_{3}$ gas in an $\mathrm{AlGaN} / \mathrm{GaN}$ HEMT with $\mathrm{ZnO}$ nanorods. ${ }^{(20,21)}$

The responses of the AlGaN/GaN HEMT functionalized by $\mathrm{ZnO}$ nanorods to sequential $10 \mathrm{~s}$ exposures of $100 \% \mathrm{~N}_{2}$ and $300-100000$ ppm $\mathrm{CO}_{2}$ in dry air at 150 and $300{ }^{\circ} \mathrm{C}$ are shown in Fig. 3. The drain bias voltage was fixed at $1 \mathrm{~V}$. The device was tested under the same conditions at 25 to $400{ }^{\circ} \mathrm{C}$ in $50{ }^{\circ} \mathrm{C}$ increments, but no response to $\mathrm{CO}_{2}$ was observed at 25,50 , and $100{ }^{\circ} \mathrm{C}$. At $150{ }^{\circ} \mathrm{C}$, the HEMT with $\mathrm{ZnO}$ nanorods started to respond to $30000 \mathrm{ppm} \mathrm{CO}_{2}$, but the drain current signal was unclear. In contrast, distinctive changes in current for exposures to various

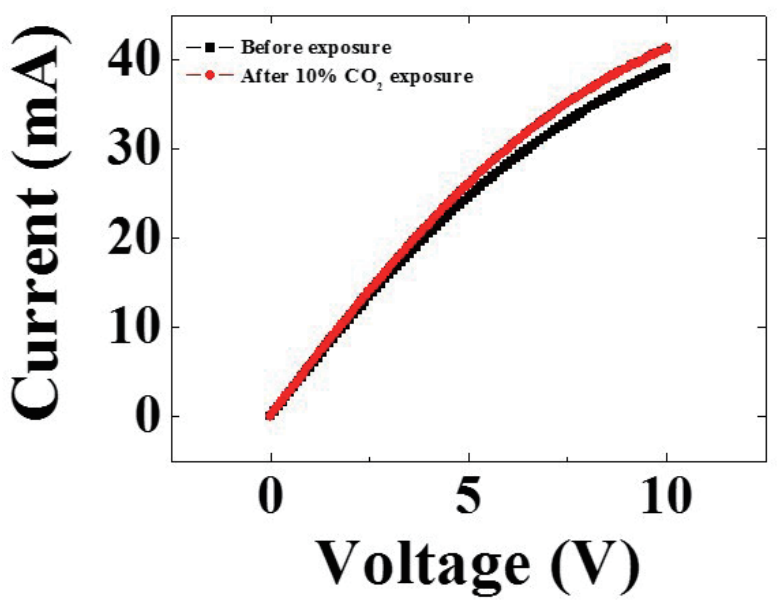

Fig. 2. (Color online) Drain current response of the HEMT sensor to air and $10 \% \mathrm{CO}_{2}$ exposure at $300{ }^{\circ} \mathrm{C}$. 


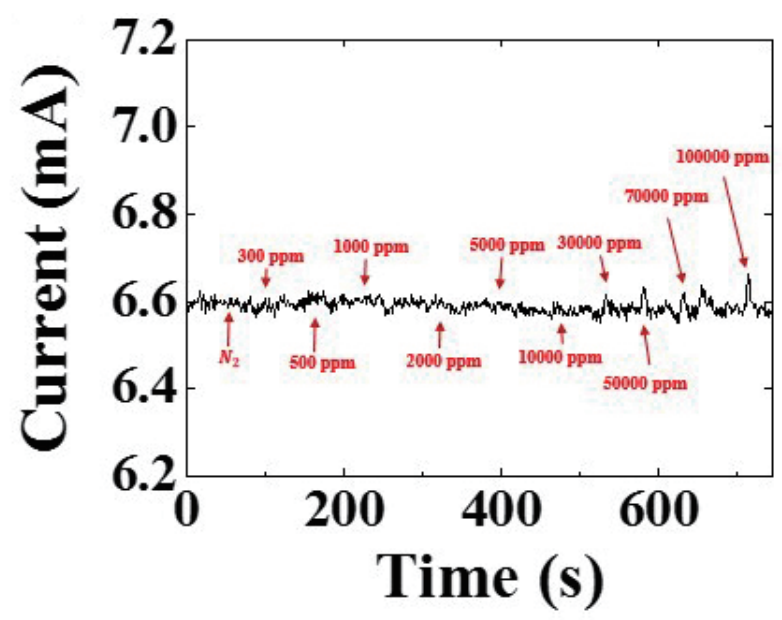

(a)

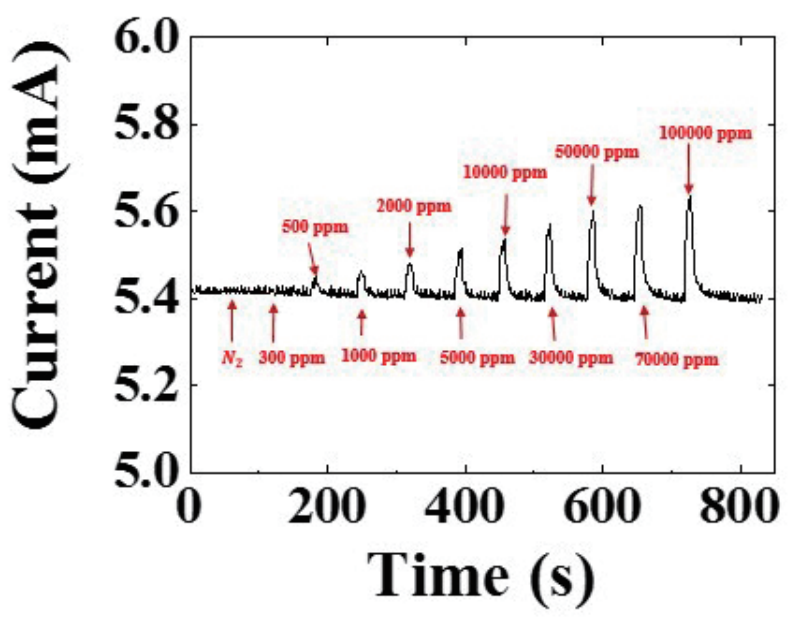

(b)

Fig. 3. (Color online) Time-dependent responses of the HEMT to $100 \% \mathrm{~N}_{2}$ and $300-100000 \mathrm{ppm} \mathrm{CO}_{2}$ at 150 and $300{ }^{\circ} \mathrm{C}$. The drain bias was $1 \mathrm{~V}$ and the gas exposure time was $10 \mathrm{~s}$.

concentrations of $\mathrm{CO}_{2}$ were observed at $300{ }^{\circ} \mathrm{C}$. The drain current returned to the original level after switching back to air. The minimum measurable concentration of $\mathrm{CO}_{2}$ was $500 \mathrm{ppm}$. The AlGaN/GaN HEMT with $\mathrm{ZnO}$ nanorods showed reliable repeatability for cyclic exposures with various concentrations of $\mathrm{CO}_{2}$ at $300{ }^{\circ} \mathrm{C}$.

Figure 4 shows the responsivity of the HEMT sensor to $300-100000 \mathrm{ppm}(10 \%)$ concentrations of $\mathrm{CO}_{2}$ at $150,200,250,300,350$, and $400{ }^{\circ} \mathrm{C}$. The responsivity is defined as $\left(I_{\mathrm{CO}_{2}}-I_{\text {air }}\right) / I_{\mathrm{CO}_{2}} \times 100(\%)$, where $I_{\mathrm{CO}_{2}}$ and $I_{\text {air }}$ are the drain currents of the HEMT at $1 \mathrm{~V}$ under $\mathrm{CO}_{2}$ and ambient air, respectively. As the $\mathrm{CO}_{2}$ concentration increases, the responsivity increases and saturates at high $\mathrm{CO}_{2}$ concentrations. The HEMT responsivity for $10 \% \mathrm{CO}_{2}$ at $300{ }^{\circ} \mathrm{C}$ was $4.31 \%$. The responsivity increased with the ambient temperature until reaching $300{ }^{\circ} \mathrm{C}$, and it decreased at 350 and $400{ }^{\circ} \mathrm{C}$. The oxygen ions adsorbed on the $\mathrm{ZnO}$ surface exist in the form of $\mathrm{O}_{2}^{-}, \mathrm{O}^{-}$, and $\mathrm{O}^{2-}$. The $\mathrm{O}_{2}^{-}, \mathrm{O}^{-}$, and $\mathrm{O}^{2-}$ ions are stable below $100{ }^{\circ} \mathrm{C}$, between 100 and $300{ }^{\circ} \mathrm{C}$, and above $300^{\circ} \mathrm{C}$, respectively..$^{(1,31)}$ The rate of the forward reaction of Reaction (1) may increase with the concentration of adsorbed oxygen ions, $\mathrm{O}^{-}$, up to $300{ }^{\circ} \mathrm{C}$; hence, the device shows maximum responsivity at $300{ }^{\circ} \mathrm{C}$. This temperature dependence of the responsivity can also be found in the case of $\mathrm{ZnO}$ thin-film $\mathrm{CO}_{2}$ sensors. ${ }^{(1)}$

The responsivity at $300{ }^{\circ} \mathrm{C}$ was modeled using the dissociative Langmuir isotherm given below, as shown in Fig. $5{ }^{(6,32)}$

$$
R=\frac{\alpha\left(K_{e q} \cdot C\right)^{\frac{1}{2}}}{1+\left(K_{e q} \cdot C\right)^{\frac{1}{2}}}
$$

where $R$ is the responsivity, $\alpha$ is the proportionality constant, $K_{e q}$ is the equilibrium constant of the adsorption, and $C$ is the concentration of $\mathrm{CO}_{2}$. The plot shows good agreement with the 


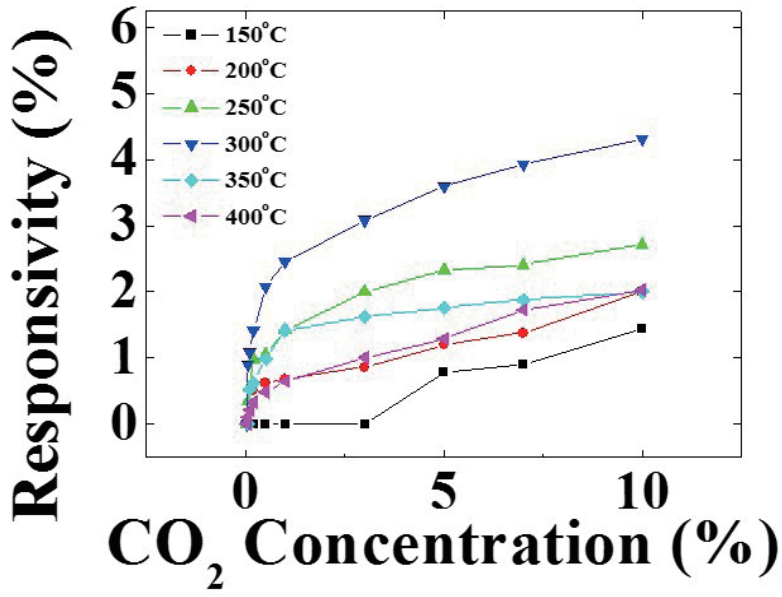

Fig. 4. (Color online) Responsivity of the HEMT sensor to different concentrations of $\mathrm{CO}_{2}$ at 150,200 , $250,300,350$, and $400{ }^{\circ} \mathrm{C}$.

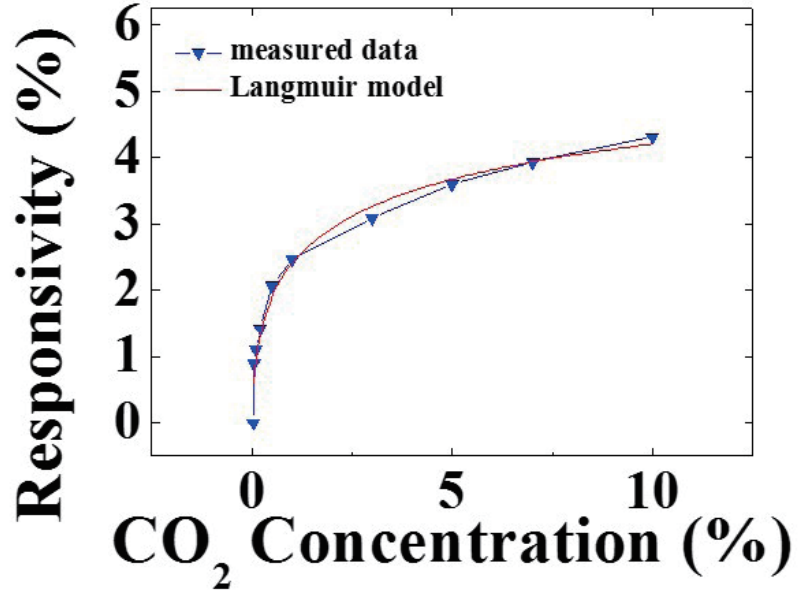

Fig. 5. (Color online) Responsivity of the HEMT to different concentrations of $\mathrm{CO}_{2}$ at $300{ }^{\circ} \mathrm{C}$ and its Langmuir isotherm fitting model.

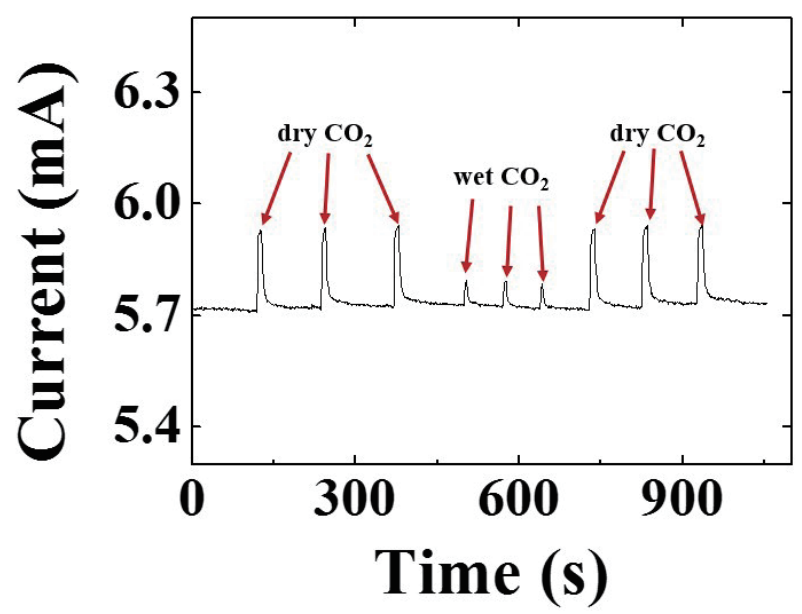

Fig. 6. (Color online) Change in drain current of the HEMT at $300{ }^{\circ} \mathrm{C}$ for cyclic exposures of dry, wet, and dry $10 \% \mathrm{CO}_{2}$.

measured and calculated data. The equilibrium constant of the AlGaN/GaN HEMT with $\mathrm{ZnO}$ nanorods at $300^{\circ} \mathrm{C}$ was 0.346 .

The effect of humidity on $\mathrm{CO}_{2}$ sensing was investigated. Figure 6 shows the change in drain current of the HEMT with $\mathrm{ZnO}$ nanorods at $300{ }^{\circ} \mathrm{C}$ for cyclic exposures of dry, wet, and dry $10 \% \mathrm{CO}_{2}$. The bias voltage was $1 \mathrm{~V}$, and each $10 \mathrm{~s}$ of $\mathrm{CO}_{2}$ exposure was repeated three times. The relative humidity was $77 \%$ for a wet $\mathrm{CO}_{2}$ environment at $300{ }^{\circ} \mathrm{C}$. The change in drain current decreased by $64 \%$ under a humid ambient condition compared with the case of dry $\mathrm{CO}_{2}$ exposure, even at a high temperature of $300{ }^{\circ} \mathrm{C}$. Under wet $\mathrm{CO}_{2}$ conditions, $\mathrm{H}_{2} \mathrm{O}$ molecules were adsorbed on the surface of $\mathrm{ZnO}$ nanorods and prevented $\mathrm{CO}_{2}$ molecules from reacting with oxygen ions on the active sites of the nanorods, reducing the change in drain current. ${ }^{(25)}$ 
This deteriorating effect of humidity can be overcome by employing polyimide-based moisture barrier encapsulation with a high glass transition temperature, which enables $\mathrm{CO}_{2}$ molecules to penetrate but blocks $\mathrm{H}_{2} \mathrm{O}{ }^{(6-9,25)}$

\section{Conclusions}

An AlGaN/GaN HEMT with $\mathrm{ZnO}$ nanorods on the gate region was shown to be capable of $\mathrm{CO}_{2}$ detection from $150{ }^{\circ} \mathrm{C}$. The device demonstrated reliable sensing characteristics for the $\mathrm{CO}_{2}$ concentration range from 500 to $100000 \mathrm{ppm}$ at $300{ }^{\circ} \mathrm{C}$. The maximum responsivity of the sensor for $10 \% \mathrm{CO}_{2}$ exposure was $4.31 \%$. The $\mathrm{CO}_{2}$-sensing capability of the HEMT increased with ambient temperature until it reached $300{ }^{\circ} \mathrm{C}$; then, it decreased at 350 and $400{ }^{\circ} \mathrm{C}$. When wet $\mathrm{CO}_{2}$ was introduced to the HEMT sensor, the responsivity dropped by $64 \%$ at $300{ }^{\circ} \mathrm{C}$ because the active sites of the $\mathrm{ZnO}$ nanorods were blocked by $\mathrm{H}_{2} \mathrm{O}$ molecules.

\section{Acknowledgments}

This research was supported by the Basic Science Research Program through the National Research Foundation of Korea (NRF) funded by the Ministry of Education (2018R1D1A1A09083988, 2020R1I1A3A0403783711), and the Nano·Material Technology Development Program through the NRF funded by the Ministry of Science, ICT and Future Planning (2015M3A7B7045185).

\section{References}

1 P. K. Kannan, R. Saraswathi, and J. B. Rayappan: Ceram. Int. 40 (2014) 13115. https://doi.org/10.1016/ j.ceramint.2014.05.011

2 O. Lupan, L. Chow, S. Shishiyanu, E. Monaico, T. Shishiyanu, V. Sontea, B. R. Cuenya, A. Naitabdi, S. Park, and A. Schulte: Mater. Res. 44 (2009) 63. https://doi.org/10.1016/j.materresbull.2008.04.006

3 R. Monastersky: Nature 497 (2013) 7447. https://doi.org/10.1038/497013a

4 T. A. Vincent and J. W. Gardner: Sens. Actuators, B 236 (2016) 954. https://doi.org/10.1016/j.snb.2016.04.016

5 T. Anderson, F. Ren, S. Pearton, B. S. Kang, H. Wang, C. Chang, and J. Lin: Sensors 9 (2009) 4669. https://doi. org $/ 10.3390 / \mathrm{s} 90604669$

6 K. H. Baik, S. Jung, F. Ren, S. J. Pearton, and S. Jang: ECS J. Solid State Sci. Technol. 7 (2018) Q3009. https:// doi.org/10.3390/s90604669

7 S. Jung, K. H. Baik, F. Ren, S. J. Pearton, and S. Jang: IEEE Sens. J. 17 (2017) 5817. https://doi.org/10.1109/ JSEN.2017.2733343

8 S. Jung, K. H. Baik, and S. Jang: ECS Trans. 77 (2017) 33. https://doi.org/10.1149/07706.0033ecst

9 S. Jung, K. H. Baik, F. Ren, S. J. Pearton, and S. Jang: IEEE Electron Device Lett. 38 (2017) 657. https://doi. org/10.1109/LED.2017.2681114

10 S. Jang, S. Jung, and K. H. Baik: Thin Solid Films 660 (2018) 646. https://doi.org/10.1016/j.tsf.2018.04.027

11 S. Jang, P. Son, J. Kim, S. Lee, and K. H. Baik: Sens. Actuators, B 222 (2016) 43. https://doi.org/10.1016/ j.snb.2015.08.056

12 H. Kim, K. H. Baik, F. Ren, S. J. Pearton, and S. Jang: ECS Trans. 61 (2014) 353. https://doi. org/10.1149/06104.0353ecst

13 K. H. Baik, H. Kim, S. Lee, E. Lim, S. J. Pearton, F. Ren, and S. Jang: Appl. Phys. Lett. 104 (2014) 072103. https://doi.org/10.1063/1.4866010

14 Y. L. Wang, F. Ren, W. Lim, S. J. Pearton, K. H. Baik, S. Hwang, Y. G. Seo, and S. Jang: Curr. Appl. Phys. 10 (2010) 1029. https://doi.org/10.1016/j.cap.2009.12.034

15 K. H. Baik, J. Kim, and S. Jang: Sens. Actuators, B 238 (2017) 462. https://doi.org/10.1016/j.snb.2016.07.091 
16 S. Jang, J. Kim, and K. H. Baik: J. Electrochem. Soc. 163 (2016) B456. https://doi.org/10.1149/2.1161608jes

17 K. H. Baik, J. Kim, and S. Jang: ECS Trans. 72 (2016) 23. https://doi.org/10.1149/07205.0023ecst

18 H. Kim and S. Jang: Curr. Appl. Phys. 13 (2013) 1746. https://doi.org/10.1016/j.cap.2013.07.008

19 H. Kim, W. Lim, J. Lee, S. J. Pearton, F. Ren, and S. Jang: Sens. Actuators, B 164 (2012) 64. https://doi. org/10.1016/j.snb.2012.01.067

20 S. Jung, K. H. Baik, F. Ren, S. J. Pearton, and S. Jang: ECS J. Solid State Sci. Technol. 7 (2018) Q3020. https:// doi.org/10.1149/2.0041807jss

21 S. Jung, K. H. Baik, F. Ren, S. J. Pearton, and S. Jang: J. Vac. Sci. Technol. B. 35 (2017) 042201. https://doi. org/10.1116/1.4989370

22 S. Jung, K. H. Baik, F. Ren, S. J. Pearton, and S. Jang: J. Electrochem. Soc. 164 (2017) B417. https://doi. org/10.1149/2.0781709jes

23 S. Jung, K. H. Baik, and S. Jang: ECS Trans. 77 (2017) 121. https://doi.org/10.1149/07706.0121ecst

24 S. Jung, K. H. Baik, and S. Jang: ECS Trans. 75 (2017) 9. https://doi.org/10.1149/07540.0009ecst

25 S. Jang, S. Jung, and K. H. Baik: Sensors 20 (2020) 835. https://doi.org/10.3390/s20030835

26 S. Jang, S. Jung, and K. H. Baik: ECS J. Solid State Sci. Technol. 8 (2019) Q85. https://doi. org/10.1149/2.0131904jss

27 J. Kim, K. H. Baik, and S. Jang: Curr. Appl. Phys. 16 (2016) 221. https://doi.org/10.1016/j.cap.2015.11.014

28 K. H. Baik, H. Kim, J. Kim, S. Jung, and S. Jang: Appl. Phys. Lett. 103 (2013) 091107. https://doi. org/10.1063/1.4819847

29 L. E. Greene, M. Law, J. Goldberger, F. Kim, J. C. Johnson, Y. Zhang, R. J. Saykally, and P. Yang: Angew. Chem. 42 (2003) 3031. https://doi.org/10.1002/anie.200351461

30 K. H. Baik, J. Kim, and S. Jang: Appl. Surf. Sci. 435 (2018) 592. https://doi.org/10.1016/j.apsusc.2017.11.038

31 K. Wetchakun, T. Samerjal, N. Tamaekong, C. Liewhiran, C. Siriwong, V. Kruefu, A. Wisitsoraat, A. Tuantranont, and S. Phanichphant: Sens. Actuators, B 160 (2011) 580. https://doi.org/10.1016/j.snb.2011.08.032

32 C. Wen, Q. Ye, S. L. Zhang, and D. Wu: Sens. Actuators, B 223 (2016) 791. https://doi.org/10.1016/j.snb.2015.10.019

\section{About the Authors}

Kwang Hyeon Baik received his B.S. degree from Yonsei University, Seoul, Korea, in 1998 and his Ph.D. degree in materials science and engineering from University of Florida, Gainesville, Florida, in 2004. He worked at the Photonics Lab at Samsung Advanced Institute of Technology from 2005 to 2008 and also worked at Korea Electronics Technology Institute from 2009 to 2011. Since 2012, he has been with Hongik University, Sejong, Korea as an associate professor. His current research interests include the growth and characterization of GaN- and $\mathrm{ZnO}$-based light-emitting diodes and hydrogen gas sensors, and III-V semiconductor-based electronic devices. (khbaik@hongik.ac.kr)

Soohwan Jang received his B.S. degree from the Department of Chemical Engineering, Seoul National University, Seoul, Korea, in 2003 and his Ph.D. degree from the Department of Chemical Engineering, University of Florida, Gainesville, Florida, in 2007. From 2007 to 2009, he worked at Samsung Electronics. He has been a professor at the Department of Chemical Engineering, Dankook University, since 2009. His research interests include nitride- and oxide-based sensors, light-emitting diodes, and integrated electronic devices.

(jangmountain@dankook.ac.kr) 